\title{
The positive effects of running exercise on hippocampal astrocytes in a rat model of depression
}

\author{
Yue Li ${ }^{1,2}$, Yanmin Luo ${ }^{3}$, Jing Tang ${ }^{1,2}$, Xin Liang ${ }^{2,4}$, Jin Wang ${ }^{1,2}$, Qian Xiao ${ }^{5}$, Peilin Zhu ${ }^{2,3}$, Kai Xiao ${ }^{1,2}$, Lin Jiang ${ }^{6}$, \\ Xiaoyun Dou ${ }^{7}$, Chunxia Huang ${ }^{3}$, Yuhan $X_{i e^{1,2}}$ and Yong Tang $\mathbb{B}^{1,2}$
}

\begin{abstract}
Running exercise has been shown to alleviate depressive symptoms, but the mechanism of its antidepressant effect is still unclear. Astrocytes are the predominant cell type in the brain and perform key functions vital to central nervous system (CNS) physiology. Mounting evidence suggests that changes in astrocyte number in the hippocampus are closely associated with depression. However, the effects of running exercise on astrocytes in the hippocampus of depression have not been investigated. Here, adult male rats were subjected to chronic unpredictable stress (CUS) for 5 weeks followed by treadmill running for 6 weeks. The sucrose preference test (SPT) was used to assess anhedonia of rats. Then, immunohistochemistry and modern stereological methods were used to precisely quantify the total number of glial fibrillary acidic protein (GFAP) ${ }^{+}$astrocytes in each hippocampal subregion, and immunofluorescence was used to quantify the density of bromodeoxyuridine $(\mathrm{BrdU})^{+}$and $\mathrm{GFAP}^{+}$cells in each hippocampal subregion. We found that running exercise alleviated CUS-induced deficit in sucrose preference and hippocampal volume decline, and that CUS intervention significantly reduced the number of GFAP ${ }^{+}$cells and the density of $\mathrm{BrdU}^{+} / \mathrm{GFAP}^{+}$cells in the hippocampal CA1 region and dentate gyrus (DG), while 6 weeks of running exercise reversed these decreases. These results further confirmed that running exercise alleviates depressive symptoms and protects hippocampal astrocytes in depressed rats. These findings suggested that the positive effects of running exercise on astrocytes and the generation of new astrocytes in the hippocampus might be important structural bases for the antidepressant effects of running exercise.
\end{abstract}

\section{Introduction}

Depression is a common mental disorder with an increasing mortality rate $^{1}$ and understanding the mechanisms of depression and antidepressant therapeutics is crucial. Numerous studies have demonstrated that the etiology of depression includes not only stressinduced mental issues but also stress-induced pathological lesions, particularly in encephalic regions ${ }^{2}$, especially

Correspondence: Yong Tang (ytang062@163.com)

'Department of Histology and Embryology, Chongqing Medical University, 400016 Chongqing, P. R. China

${ }^{2}$ Laboratory of Stem Cells and Tissue Engineering, Chongqing Medical University, 400016 Chongqing, P. R. China

Full list of author information is available at the end of the article the hippocampus and prefrontal cortex (PFC). The hippocampus is associated with cognition and memory ${ }^{3}$, and it has been reported to modulate depressed $\operatorname{mood}^{4,5}$. Postmortem studies of depression patients have demonstrated that hippocampal volume is decreased in these patients compared to control subjects ${ }^{6,7}$. Similar findings have been reported in animal models of depression ${ }^{8,9}$. Furthermore, Czéh et al. have found that the stressinduced reduction in astroglial number is highly correlated with a reduction in hippocampal volume ${ }^{10}$. Astrocytes are the most abundant glial cells in the central nervous system (CNS) and account for $20-40 \%$ of all glial cells in the human brain ${ }^{11-13}$. Increasing evidence has indicated that astrocyte pathology in several encephalic 
regions might contribute to the mechanism of depression in both depressed subjects and animal models ${ }^{14-18}$. Human postmortem studies have revealed that the density of astrocytes in the hippocampus is lower in depressed subjects than control subjects ${ }^{19,20}$. Furthermore, using stereological methods, Czéh et al. observed astroglial loss in the hippocampus of male tree shrews after long-term psychosocial stress ${ }^{10}$. The hippocampal formation is a well-organized structure that has a complex anatomical organization and cellular composition, and its subregions have specific structural connectivity and functional roles $^{21}$. Mild chronic psychogenic stress typically leads to dendrite retraction in CA3 pyramidal neurons, but not CA1 pyramidal neurons or granule cells in the dentate gyrus (DG) $)^{22,23}$. The CA1 becomes susceptible to acute stress after stress sensitization, and chronic stress can reduce synaptic plasticity in both the CA1 region and $\mathrm{DG}^{24}$. Adult neurogenesis, which has been suggested to play an important role in depression, specifically occurs in the $\mathrm{DG}^{25}$. All of these findings indicate that different subfields of the hippocampus might respond differently to stress. However, the change in the number of astrocytes that occurs in each hippocampal subregion in depressed animals is unknown. Moreover, new glial cells are produced in the CNS of adult mammals through gliogen$\mathrm{esis}^{26}$, and the integration of newborn cells into the neuronal network is important for the function of the $\mathrm{CNS}^{27}$. However, whether changes in newborn astrocytes in the hippocampal subregions affect astroglial loss in depressed animals is still unclear. To explore these issues, an unbiased stereological technique was used to study the total number of astrocytes, and immunofluorescence was used to study the density of bromodeoxyuridine $(\mathrm{BrdU})^{+} /$ glial fibrillary acid protein $(\mathrm{GFAP})^{+}$cells in each of three hippocampal subregions (the CA1 region, CA2/3 region, and DG) in a chronic unpredictable stress (CUS) rat model of depression.

Running exercise, as a simple behavioral therapy, has been widely demonstrated to have antidepressant effects ${ }^{28}$. Studies have reported that physical exercise is associated with a greater reduction in depressive symptomology than no treatment or placebo in depression ${ }^{29}$. Our previous studies have demonstrated that treadmill exercise can improve the depressive-like behaviors induced by CUS in rats $^{30,31}$. However, the mechanisms underlying these antidepressant effects of running exercise are still unknown. Several studies have found that the improvements in depressive symptoms ${ }^{20}$ and depressive-like behaviors ${ }^{10,32,33}$ induced by antidepressant therapy are accompanied by changes in astrocytes. Furthermore, Cui et al. showed that astrocyte-specific loss of Kir4.1 in the lateral habenula can alleviate the depression-like symptoms of depressed rats ${ }^{16}$, furthermore, Cao et al. showed that selective activation of astroglial $\mathrm{Ca}^{2+}$ signaling can stimulate endogenous ATP release from astrocytes and induce antidepressant-like effects in depressed mice ${ }^{17}$. These studies indicate that astrocytes might play an extremely important role in the mechanism of antidepressant therapy. Studies have reported that running exercise can increase the density of astrocytes in the CA1 region of the hippocampus ${ }^{34}$, parietal cortex and dorsolateral striatum ${ }^{35}$ in normal rats and in the hippocampus of rats with type 1 diabetes mellitus $(\mathrm{T} 1 \mathrm{DM})^{36}$. Moreover, Ehninger and Kempermann ${ }^{37}$ found that running exercise can increase the density of $\mathrm{BrdU}^{+} /$ $S 100 \beta^{+}$cells in the cingulate, motor and visual cortex in normal mice. Similarly, running exercise has been shown to increase the number of newborn astrocytes in the hippocampus in normal adult rats ${ }^{38}$. These studies indicated that running exercise can increase the density of astrocytes and promote the generation of new astrocytes in normal rodents and rats with T1DM, but whether running exercise can reverse astroglial loss in the hippocampus in depression is poorly understood.

In the current study, we hypothesized that running exercise alleviates depression through increasing the number of astrocytes and enhancing the generation of new astrocytes in the hippocampus of rats with CUSinduced depression. To verify this hypothesis, the antidepressant effects of running exercise were first assessed with the sucrose preference test (SPT). Then, stereological and immunofluorescence techniques were used to investigate astrocyte and newly generated astrocytes in three subregions of the hippocampus.

\section{Materials and methods \\ Animals}

Sixty male Sprague-Dawley rats (weight $150 \pm 10 \mathrm{~g}$ ) from Chongqing Medical University (Chongqing, PR China) were housed in groups (5 rats per cage) at a constant temperature $\left(22 \pm 2^{\circ} \mathrm{C}\right)$ on a 12-h light/dark cycle (7 AM-7 PM) and provided free access to food and water. During the animal experiment, the animals in each group were treated by the investigators without blinding. All procedures were conducted in accordance with the National Institutes of Health Guide for the Care and Use of Laboratory Animals and were consistent with the Chongqing Medical University Care and Use of Laboratory Animals guidelines.

\section{CUS intervention}

All rats were allowed to habituate to the housing conditions for 2 weeks. Next, 60 rats were randomly divided into the control group $(n=23)$ (nonstressed rats) and the CUS group $(n=37)$ (stressed rats). Each rat in the CUS group was subjected to a sequence of 10 different stressors (cold/heat stress, light changes (on/off), noise, food or/and water deprivation, empty bottle, wet bedding, electric shock, 1-h restraint, tail pinching and cage tilting) 
for 5 weeks (two stressors per day) (Fig. 1, Table 1). This procedure was adapted from Willner et al. ${ }^{39}$, Banasr et al. ${ }^{40}$, and Seney et al. ${ }^{41}$. The control group was housed under normal conditions. The effects of stress on the hedonic state of the rats were assessed with the SPT and body weights were measured each weekend ${ }^{39}$. Then, the rats in the CUS group were randomly divided into the CUS/standard group $(n=17)$ (stressed rats not subjected to running exercise) and the CUS/running group $(n=20)$ (stressed rats subjected to running exercise).

\section{Running exercise protocol and BrdU injection}

In the CUS/running group, the animals ran on a sixlane motorized treadmill for $20 \mathrm{~min}$ per day, 5 days per week for 6 weeks. The running speed was gradually increased from 10 to $20 \mathrm{~m} / \mathrm{min}$ during the first week and then maintained at $20 \mathrm{~m} / \mathrm{min}$ for the next 5 weeks ${ }^{42-44}$. The control group and the CUS/standard group were housed under conditions are not subjected to running exercise. BrdU $(20 \mathrm{mg} / \mathrm{mL}$, dissolved in $0.9 \%$ saline solution; B5002, Sigma, USA) was injected ( $5 \mathrm{ml} / \mathrm{kg}$, i.p.) once a day for 7 consecutive days, during the first week of running exercise $e^{45-47}$.

\section{Body weight measurement}

The body weights of the rats in each group were obtained before sucrose consumption every weekend.

\section{SPT}

The SPT was used in this study to assess anhedonia. The SPT was performed each weekend at 8:30 AM after body weight measurement. During the test, the rats were allowed access to two bottles of water, the one containing fresh water and the other containing $1 \%$ sucrose solution, for $24 \mathrm{~h}$ and left undisturbed. The bottle containing the sucrose solution was placed randomly on the left or right side of the cage. This protocol was adapted from Willner et al. ${ }^{39}$ and Banasr et al. ${ }^{40}$. The sucrose preference rate was calculated as sucrose consumption/total liquid consumption $\times 100 \%$.

\section{Perfusion and tissue preparation}

During the following processes, all the experiments and data analyses were performed blind to treatment conditions. Five random rats from each group were deeply anesthetized by i.p. injection of $1 \%$ pentobarbital sodium $(4 \mathrm{ml} / \mathrm{kg})$ and perfused with $4 \%$ paraformaldehyde. The brains were removed and divided into two hemispheres along the sagittal

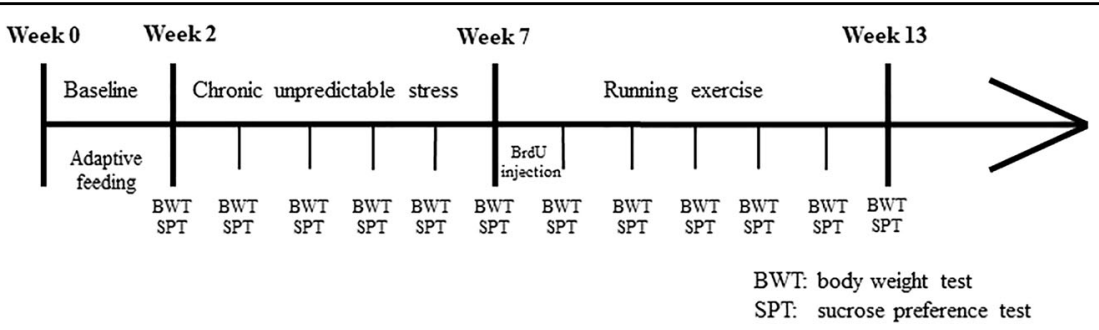

Fig. 1 Behavioral experiment timeline. The experiment lasted a total of 13 weeks. The animals were allowed to habituate to the housing conditions for 2 weeks before any experiments were initiated. The CUS rats were subjected to a sequence of 10 different stressors (two stressors per day for 5 weeks). The animal in the CUS/running group ran on a six-lane motorized treadmill for 6 weeks after CUS. Body weight and sucrose preference were assessed each weekend. CUS chronic unpredictable stress, BWT body weight test, SPT sucrose preference test.

Table 1 The schedule of CUS model intervention.

\begin{tabular}{|c|c|c|c|c|c|c|c|}
\hline Time & Monday & Tuesday & Wednesday & Thursday & Friday & Saturday & Sunday \\
\hline Week 1 & $\begin{array}{l}\text { Wet bedding } \\
\text { cage tilting }\end{array}$ & $\begin{array}{l}\text { Water deprivation } \\
\text { light off }\end{array}$ & $\begin{array}{l}\text { Electric shock } \\
\text { empty bottle }\end{array}$ & $\begin{array}{l}\text { Restraint } \\
\text { light on }\end{array}$ & $\begin{array}{l}\text { Tail pinching } \\
\text { noise }\end{array}$ & $\begin{array}{l}\text { Food deprivation } \\
\text { heat stress }\end{array}$ & $\begin{array}{l}\text { BWT } \\
\text { SPT }\end{array}$ \\
\hline Week 2 & $\begin{array}{l}\text { Wet bedding } \\
\text { noise }\end{array}$ & $\begin{array}{l}\text { Cold stress } \\
\text { empty bottle }\end{array}$ & $\begin{array}{l}\text { Cage tilting } \\
\text { tail pinching }\end{array}$ & $\begin{array}{l}\text { Water deprivation } \\
\text { food deprivation }\end{array}$ & $\begin{array}{l}\text { Electric shock } \\
\text { heat stress }\end{array}$ & $\begin{array}{l}\text { Light off } \\
\text { restraint }\end{array}$ & $\begin{array}{l}\text { BWT } \\
\text { SPT }\end{array}$ \\
\hline Week 3 & $\begin{array}{l}\text { Light on } \\
\text { tail pinching }\end{array}$ & $\begin{array}{l}\text { Cage tilting } \\
\text { light off }\end{array}$ & $\begin{array}{l}\text { Water deprivation } \\
\text { restraint }\end{array}$ & $\begin{array}{l}\text { Wet bedding } \\
\text { empty bottle }\end{array}$ & $\begin{array}{l}\text { Noise } \\
\text { electric shock }\end{array}$ & $\begin{array}{l}\text { Heat stress } \\
\text { food deprivation }\end{array}$ & $\begin{array}{l}\text { BWT } \\
\text { SPT }\end{array}$ \\
\hline Week 4 & $\begin{array}{l}\text { Wet bedding } \\
\text { water deprivation }\end{array}$ & $\begin{array}{l}\text { Electric shock } \\
\text { empty bottle }\end{array}$ & $\begin{array}{l}\text { Light off } \\
\text { cold stress }\end{array}$ & $\begin{array}{l}\text { Cage tilting } \\
\text { restraint }\end{array}$ & $\begin{array}{l}\text { Noise } \\
\text { tail pinching }\end{array}$ & $\begin{array}{l}\text { Food deprivation } \\
\text { light on }\end{array}$ & $\begin{array}{l}\text { BWT } \\
\text { SPT }\end{array}$ \\
\hline Week 5 & $\begin{array}{l}\text { Noise } \\
\text { food deprivation }\end{array}$ & $\begin{array}{l}\text { Water deprivation } \\
\text { heat stress }\end{array}$ & $\begin{array}{l}\text { Electric shock } \\
\text { light on }\end{array}$ & $\begin{array}{l}\text { Wet bedding } \\
\text { tail pinching }\end{array}$ & $\begin{array}{l}\text { Light off } \\
\text { empty bottle }\end{array}$ & $\begin{array}{l}\text { Cage tilting } \\
\text { restraint }\end{array}$ & $\begin{array}{l}\text { BWT } \\
\text { SPT }\end{array}$ \\
\hline
\end{tabular}

CUS chronic unpredictable stress, BWT body weight test, SPT sucrose preference test. 
suture. The right or left hemisphere of each rat brain was selected at random. After perfusion, the hemispheres were fixed in $4 \%$ paraformaldehyde for at least $24 \mathrm{~h}$ and then immersed in increasing concentrations (10,20, and 30\%) of sucrose in $0.1 \mathrm{M}$ PBS ( $\mathrm{pH}$ 7.4) until equilibrium was reached. Then, hemispheres were rapidly frozen at $-60^{\circ} \mathrm{C}$ and cut into $50-\mu \mathrm{m}$ thick serial sections on a cryostat microtome (CM1860, Leica, Germany). The sections were stored at $-20^{\circ} \mathrm{C}$ after being rinsed with $0.01 \mathrm{M} \mathrm{PBS}$ and $75 \%$ alcohol. Every 6th section containing the hippocampus was selected for analysis in this study. On average, 20 sections of the hippocampus were sampled per hemisphere.

\section{Cresyl violet staining and volume estimation}

The sections were stained with cresyl violet to help delineate the boundary of the hippocampus. Using an anatomical microscope $(1.25 \times)$, the grid points located on the hippocampus were counted (Fig. 2A). The total hippocampus volume and the volume of each hippocampal subregion were estimated according to the Cavalieri's principle ${ }^{48,49}: \mathrm{V}=\mathrm{t} \times \mathrm{a}(\mathrm{p}) \times \Sigma \mathrm{P}$, where $\mathrm{V}$ is volume of the hippocampus or one of the hippocampal subregions, $t$ is the tissue block thickness $(0.6 \mathrm{~mm}), \mathrm{a}(\mathrm{p})$ is the area associated with each grid point $\left(0.09 \mathrm{~mm}^{2}\right)$, and $\Sigma \mathrm{P}$ is the total number of grid points located on the hippocampus or one of the hippocampal subregions per rat.

\section{Immunohistochemistry}

The sections were rinsed with $0.01 \mathrm{M}$ PBS (pH 7.4) three times for $10 \mathrm{~min}$ each and thoroughly rinsed with $0.01 \mathrm{M}$ PBS containing $0.3 \%$ Triton X-100 and $0.1 \%$ Tween-20 (PBS $+\mathrm{T})$. Unless otherwise stated, all washes and incubations were performed in 6-well Netwell plates at room temperature $\left(\mathrm{RT}, 21-23^{\circ} \mathrm{C}\right)$ with gentle agitation. Then, the sections were incubated in blocking buffer, $1 \%$ fetal bovine serum and 5\% SP 9001A (normal goat serum) diluted in PBS $+\mathrm{T}$ for $2 \mathrm{~h}$ at $37^{\circ} \mathrm{C}$ followed by a rabbit anti-GFAP primary antibody (ab7260, Abcam, UK, 1:2000) diluted in the abovedescribed blocking buffer for $72 \mathrm{~h}$ at $4{ }^{\circ} \mathrm{C}$. After being washed with $\mathrm{PBS}+\mathrm{T}$, the sections were incubated with SP 9001-B (biotinylated goat anti-rabbit immunoglobulin, 1:20) diluted in PBS $+\mathrm{T}$ for $24 \mathrm{~h}$ at $4{ }^{\circ} \mathrm{C}$ and SP 9001-C (biotin-HRP-streptavidin) for $4 \mathrm{~h}$ at $37^{\circ} \mathrm{C}$. Then, the sections were transferred to diaminobenzidine (DAB) solution (ZLI-9018, ZSGB, China) for $\sim 10 \mathrm{~min}$. After being washed with distilled water and 0.01 M PBS, the sections were mounted onto glass slides and dehydrated by sequential immersion in a gradient of ethanol solutions (70, 80, 90, 100, and 100\%, 5 min each) and xylene (three times, $10 \mathrm{~min}$ each). In order to make sure that the antibody penetrated the full height of the tissue, each stained section was carefully checked from the top to the bottom of the section.

\section{Stereological analysis}

Based on the morphological features of the neurons in the hippocampus ${ }^{50}$, the $\mathrm{CA} 1$ region, $\mathrm{CA} 2 / 3$ region, and DG were delineated at $\times 2.5$ magnification (Supplementary, Fig. 1A) with a stereological system (ZEISS, Germany). The area sampling fraction was set to $2 \%$. Optical disector counting frames were placed in the delineated regions of the sections in a systematic, random fashion so that each section had an equal probability of being sampled and the interval between each section and each counting site was constant. The "guard zone", which was set at $3 \mu \mathrm{m}$, was placed at the top surface of the sections, and the number of $\mathrm{GFAP}^{+}$cells was counted through a depth of $15 \mu \mathrm{m}$ below the "guard zone" (the height of the disector). The total number of astrocytes $(\mathrm{N})$ was estimated according to the following equation (for the stereological sampling scheme, see Supplementary, Fig. 1B and Table 2): $n=\Sigma \mathrm{Q}^{-} \times 1 / s s f \times 1 /$ asf $\times 1 / h s f$, where $\Sigma \mathrm{Q}^{-}$ is the number of $\mathrm{GFAP}^{+}$cells actually counted in the specimens, $s s f$ is the section sampling fraction, asf is the area sampling fraction, and $h s f$ is the height sampling fraction.

\section{Immunofluorescence}

After being washed with $0.01 \mathrm{M}$ PBS and PBS $+\mathrm{T}$, the free-floating sections were incubated in blocking buffer containing $1 \%$ fetal bovine serum, 5\% SP 9001-A, and $\mathrm{PBS}+\mathrm{T}$ for $2 \mathrm{~h}$ at $37^{\circ} \mathrm{C}$, and then stained with a rabbit anti-GFAP primary antibody for $48 \mathrm{~h}$ at $4{ }^{\circ} \mathrm{C}$. The next morning, the sections were stained with a rat anti-BrdU primary antibody (ab6326, Abcam, UK, 1:500) for $48 \mathrm{~h}$ at $4{ }^{\circ} \mathrm{C}$ (after the treatment with $2 \mathrm{~mol} / \mathrm{l} \mathrm{HCl}$ for $50 \mathrm{~min}$ at $37^{\circ} \mathrm{C}$ and boric acid for $20 \mathrm{~min}$ at room temperature). After the sections were washed with $\mathrm{PBS}+\mathrm{T}$ for $30 \mathrm{~min}$, the primary antibodies were detected with fluorophoreconjugated IgG. The sections were incubated at $37^{\circ} \mathrm{C}$ for $2 \mathrm{~h}$ with goat anti-rabbit IgG DyLight 549 (Abbkine, USA) and goat anti-rat IgG DyLight 488 (Abbkine, USA) in the dark and then washed in the dark with PBS for $30 \mathrm{~min}$. Then, the sections were mounted on gelatin-coated slides with anti-fade solution to reduce fluorescence quenching. Complete images of the hippocampus were obtained using laser scanning confocal microscopy (Nikon, Japan), and cells were counted after random and equidistant sampling in each subregions (NIS-Elements, 4.5). The complete image of immunofluorescence section was compared to the map section stained with DAPI to orientate the subregion of hippocampus. The numbers of $\mathrm{BrdU}^{+}$cells, GFAP ${ }^{+}$cells, and $\mathrm{BrdU}^{+} / \mathrm{GFAP}^{+}$cells were estimated (for the sampling scheme, see Table 3).

\section{Statistical analyses}

All data are expressed as the mean \pm standard deviation (SD). All statistical analyses were conducted using SPSS 
A

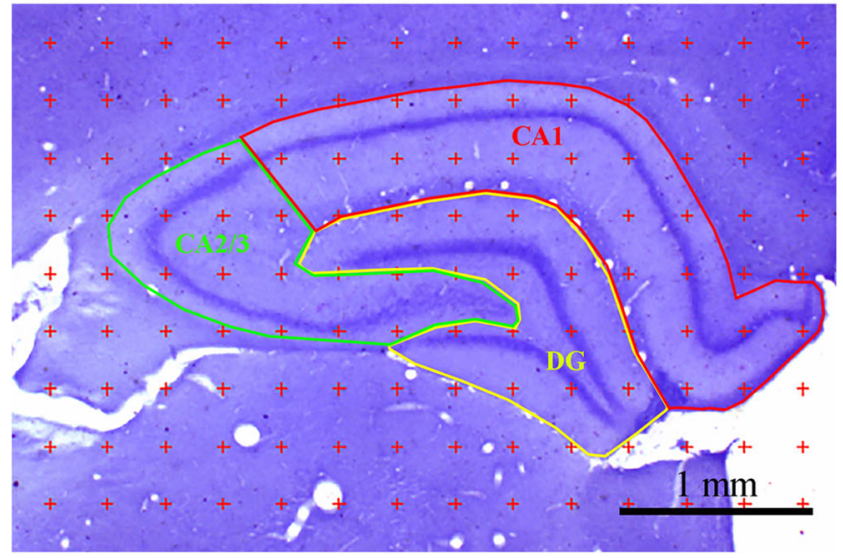

$\mathrm{B}$

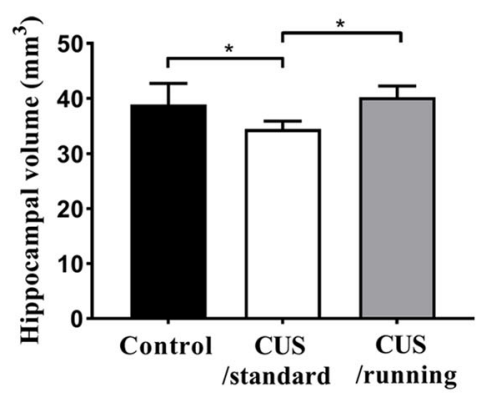

$\mathrm{D}$

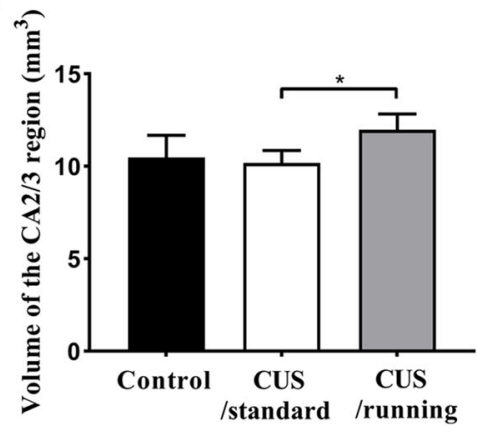

$\mathrm{C}$

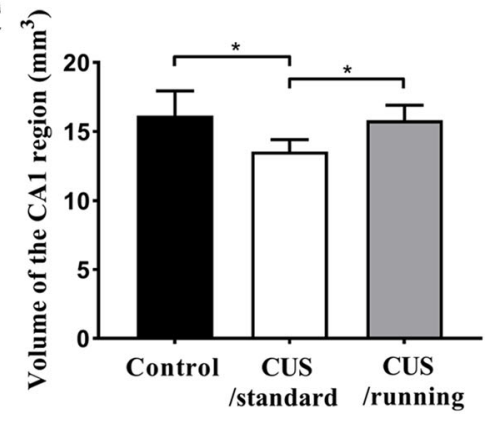

$\mathrm{E}$

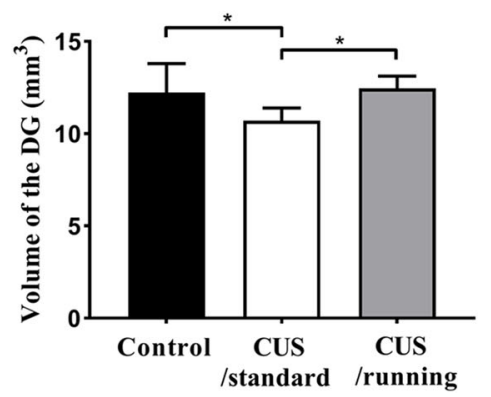

Fig. 2 Illustrations of the method used to quantify the hippocampal volume and the positive effects of running exercise on the hippocampal volume of CUS rats. A An illustration of the stereological method used to estimate the hippocampal volume. The points located on the whole hippocampus and its subregions were counted. Bar $=1 \mathrm{~mm}$. B-E The volume of the total hippocampus, the CA1 region, the CA2/3 region and DG in the control group $(n=5)$, the CUS/standard group $(n=5)$, and the CUS/cunning group $(n=5)$ (mean \pm SD). Asterisk indicates $p<0.05$. CUS chronic unpredictable stress.

19.0 statistical software. The Shapiro-Wilk test was used to evaluate whether the data were normally distributed. Levene's test was used to evaluate whether the variances were similar among the groups. The effects of CUS on sucrose preference and body weight were analyzed using repeated measures analysis of variance (ANOVA). All the data were normally distributed. If there was similar variance among groups, one-way ANOVA followed by LSD post-hoc test was used for analysis; otherwise, the Brown-Forsythe test and Tamhane T2 test were adopted for analysis. The coefficient of variation $(\mathrm{CV})$ and coefficient of error (CE) of each measurement were estimated $^{51}$. Power analysis was conducted for the results. Sample size for each experiment was chosen based on previous experience and aimed to detect at least a $p<0.05$ in the different tests applied. No animals were excluded from the current study.

\section{Results}

Running exercise alleviated anhedonia induced by CUS

At the beginning of this experiment, the body weight and sucrose preference of the CUS group were similar to 
Table 2 Sampling scheme for the estimation of GFAP ${ }^{+}$ cell numbers.

\begin{tabular}{lll}
\hline Control group & $\begin{array}{l}\text { CUS/standard } \\
\text { group }\end{array}$ & $\begin{array}{l}\text { CUS/running } \\
\text { group }\end{array}$ \\
\hline
\end{tabular}

Number of sections sampled

$\begin{array}{llll}\text { CA1 } & 16-19 & 16-19 & 17-19 \\ \text { CA2/3 } & 26-30 & 27-32 & 26-33 \\ \text { DG } & 18-22 & 19-21 & 19-22\end{array}$

Section thickness $(\mu \mathrm{m})$

$\begin{array}{llll}\text { CA1 } & 23.18 \pm 1.14 & 23.86 \pm 1.12 & 23.56 \pm 1.57 \\ \text { CA2/3 } & 24.41 \pm 1.55 & 24.48 \pm 1.07 & 24.31 \pm 1.09 \\ \text { DG } & 22.6 \pm 1.16 & 22.65 \pm 1.22 & 24.04 \pm 2.51\end{array}$

Number of counting frames sampled

$\begin{array}{llll}\text { CA1 } & 234(213-249) & 222(199-270) & 257(225-276) \\ \text { CA2/3 } & 161(152-173) & 144(125-173) & 180(158-207) \\ \text { DG } & 220(199-234) & 192(170-216) & 238(223-265)\end{array}$

Number of $\mathrm{GFAP}^{+}$cells sampled

\begin{tabular}{llll} 
CA1 & $471(435-496)$ & $399(311-490)$ & $511(430-581)$ \\
CA2/3 & $283(249-330)$ & $241(213-290)$ & $321(280-393)$ \\
DG & $496(480-530)$ & $385(344-428)$ & $537(465-607)$ \\
\hline
\end{tabular}

Section thickness is represented as mean \pm standard deviation (SD), whereas the number of counting frames and the numbers of sampled $\mathrm{GFAP}^{+}$cells are represented as mean with range in parentheses.

CUS chronic unpredictable stress, GFAP glial fibrillary acidic protein.

those of the control group. From the second week of CUS intervention, the body weights of the rats in the CUS group were significantly lower than those of the rats in the control group $(p<0.05$, Fig. 3A). During the running exercise period, the body weights of the both the rats in the CUS/standard group and those in the CUS/running group were significantly lower than the body weights of the rats in the control group, but there was no significant difference in body weight between the CUS/standard group and the CUS/running group ( $p<0.05$, Fig. 3B).

The SPT is the "gold standard" for assessing the symptoms of depression in animal models. After 5 weeks of CUS intervention, the rats in the CUS group showed a significantly lower sucrose preference than the rats in the control group $(p<0.05$, Fig. $3 C)$. At the end of the running exercise period, the rats in the CUS/standard group still showed a significantly lower sucrose preference than the rats in the control group, but the sucrose preference of the rats in the CUS/running group was statistically greater than that of the rats in the CUS/standard group $(p<0.05$, Fig. 3D). There was no significant difference in sucrose preference between the control group and the CUS/running group. These results indicated that chronic stressinduced symptoms of depression and that running exercise significantly alleviated them.
Table 3 Sampling scheme for the estimation of $\mathrm{BrdU}^{+}$, GFAP $^{+}$, and BrdU $^{+} /$GFAP $^{+}$cell.

\begin{tabular}{llll}
\hline & Control group & $\begin{array}{l}\text { CUS/standard } \\
\text { group }\end{array}$ & $\begin{array}{l}\text { CUS/running } \\
\text { group }\end{array}$ \\
\hline Number of sections sampled & & \\
CA1 & $6-9$ & $7-9$ & $7-9$ \\
CA2/3 & $5-8$ & $6-9$ & $7-9$ \\
DG & $7-9$ & $7-9$ & $8-10$
\end{tabular}

Number of counting frames sampled

$\begin{array}{llll}\text { CA1 } & 46(38-57) & 45(38-52) & 45(39-53) \\ \text { CA2/3 } & 39(27-52) & 40(34-50) & 42(35-48) \\ \text { DG } & 46(36-52) & 48(41-54) & 51(44-64)\end{array}$

Number of $\mathrm{BrdU}^{+}$cells sampled

$\begin{array}{llll}\text { CA1 } & 116(87-138) & 79(50-115) & 103(78-122) \\ \text { CA2/3 } & 80(55-89) & 60(46-95) & 88(78-105) \\ \text { DG } & 111(73-143) & 88(64-124) & 142(95-177)\end{array}$

Number of $\mathrm{GFAP}^{+}$cells sampled

$\begin{array}{llll}\text { CA1 } & 892(623-1243) & 619(418-763) & 882(620-1003) \\ \text { CA2/3 } & 770(547-1061) & 584(415-746) & 873(565-1171) \\ \text { DG } & 926(640-1330) & 647(447-819) & 1031(735-1264)\end{array}$

Number of $\mathrm{BrdU}^{+} / \mathrm{GFAP}^{+}$cells sampled

$\begin{array}{llll}\text { CA1 } & 39(29-53) & 16(10-25) & 33(28-37) \\ \text { CA2/3 } & 24(12-30) & 17(13-25) & 33(25-43) \\ \text { DG } & 40(26-64) & 24(11-36) & 57(51-63)\end{array}$

The number of counting frames and the numbers of sampled $\mathrm{BrdU}^{+}$cells, $\mathrm{GFAP}^{+}$cells, and $\mathrm{BrdU}^{+} / \mathrm{GFAP}^{+}$cells are represented as mean with range in parentheses.

CUS chronic unpredictable stress, GFAP glial fibrillary acidic protein. BrdU bromodeoxyuridine.

\section{Running exercise protected against hippocampal volume loss induced by CUS}

The mean hippocampal volume was $(38.89 \pm 3.85) \mathrm{mm}^{3}$ in the control group, $(34.41 \pm 1.46) \mathrm{mm}^{3}$ in the CUS/ standard group, $(40.23 \pm 2) \mathrm{mm}^{3}$ in the CUS/running group. These results indicated that CUS intervention significantly reduced the hippocampal volume and running exercise significantly reversed it $(p=0.02 ; p=0.005$, Fig. 2B). There was 0.883 power to detect an effect size of 1.02 for the hippocampal volume.

The mean volume of the CA1 region was $(16.15 \pm 1.6)$ $\mathrm{mm}^{3}$ in the control group, $(13.54 \pm 0.77) \mathrm{mm}^{3}$ in the CUS/ standard group, $(15.8 \pm 0.98) \mathrm{mm}^{3}$ in the CUS/running group. The mean volume of the CA2/3 region was $(10.49 \pm$ 1.06) $\mathrm{mm}^{3}$ in the control group, $(10.17 \pm 0.62) \mathrm{mm}^{3}$ in the CUS/standard group, $(11.98 \pm 0.76) \mathrm{mm}^{3}$ in the CUS/running group. The mean volume of the DG was $(12.23 \pm 1.41)$ $\mathrm{mm}^{3}$ in the control group, $(10.7 \pm 0.63) \mathrm{mm}^{3}$ in the CUS/ standard group, $(12.45 \pm 0.59) \mathrm{mm}^{3}$ in the CUS/running 

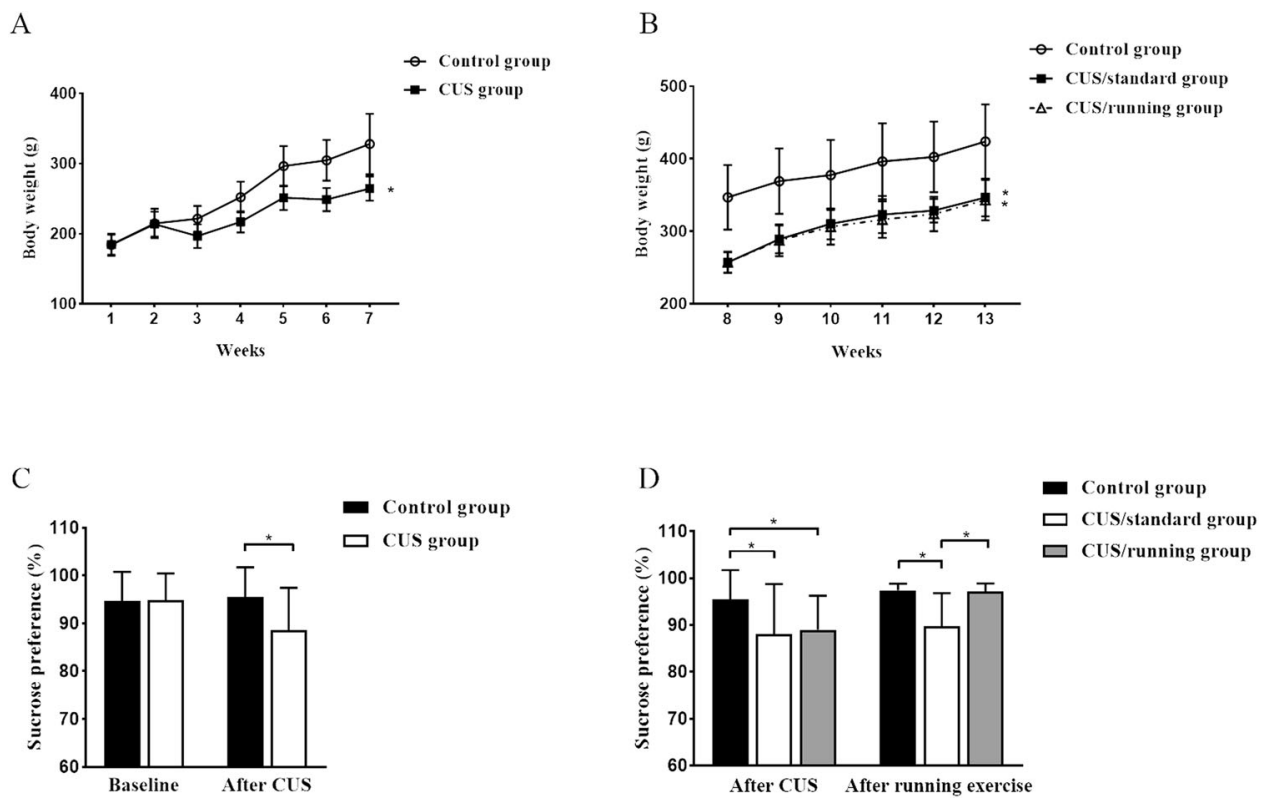

Fig. 3 The positive effects of running exercise on the depressive-like behaviors of CUS rats. A, B Body weight changes in rats at different stages (mean \pm SD). A The body weights of the control group $(n=23)$ and the CUS group $(n=37)$ during the first 7 weeks. B The body weights of the control group $(n=23)$, the CUS/standard group $(n=17)$, and the CUS/running group $(n=20)$ during the last 6 weeks. C, D The sucrose preferences of rats at different stages (mean \pm SD). C The sucrose preferences of the control group $(n=23)$ and the CUS group $(n=37)$ at the end of CUS. D The sucrose preferences of the control group $(n=23)$, the CUS/standard group $(n=17)$, and the CUS/running group $(n=20)$ at the end of the running exercise period. Asterisk indicates $p<0.05$. CUS chronic unpredictable stress.

group. These results indicated that CUS intervention significantly reduced the volume of CA1 region and DG $(p=$ $0.08 ; p=0.042$, Fig. $2 \mathrm{C}, \mathrm{E})$, and running exercise significantly increased the volume of the three hippocampal subregions $(p=0.018 ; p=0.01 ; p=0.023$, Fig. $2 \mathrm{C}-\mathrm{E})$. There was no significant difference in the volume of the CA2/3 region between the control group and the CUS/standard group ( $p=0.605$, Fig. $2 \mathrm{D})$. There were $0.892,0.846$, and 0.78 power to detect an effect size of 1.035, 0.967, and 0.891 for the volume of the CA1, CA2/3, and DG, respectively.

\section{Running exercise increased the number of astrocytes in the hippocampal subregions of CUS rats}

Representative pictures of immunohistochemistry staining with an anti-GFAP antibody are shown in Fig. 4A. The mean total number of $\mathrm{GFAP}^{+}$cells in the three hippocampal subregions in the three groups is shown in Table 4. These results indicated that the number of $\mathrm{GFAP}^{+}$cells in the CA1 region and DG was significantly lower in the CUS/ standard group than the control group $(p=0.036 ; p=$ $0.013)$, and significantly higher in the CUS/running group than the CUS/standard group $(p=0.002 ; p=0.005)$. However, the number of $\mathrm{GFAP}^{+}$cells in the CA2/3 area was not significantly different between the CUS/standard group and the control group $(p=0.067)$, but was significantly higher in the CUS/running group than the CUS/ standard group ( $p=0.001)$ (Fig. 4B). These results indicated that running exercise significantly reversed the decrease in the number of astrocytes induced by chronic stress. There were $0.959,0.967$, and 0.999 power to detect an effect size of 1.187, 1.219, and 2.101 for the number of the $\mathrm{GFAP}^{+}$ astrocytes in the CA1, CA2/3, and DG, respectively.

\section{Running exercise increased the number of newborn astrocytes in the hippocampal subregions of CUS rats}

The variation in the number of astrocytes in the hippocampus of the rats might be due to the changes in the number of newborn astrocytes. To verify this hypothesis, we performed immunofluorescence with an antibody against BrdU, a marker of newborn cells, and an antiGFAP antibody (Fig. 5A), and counted the number of $\mathrm{BrdU}^{+}$cells, $\mathrm{GFAP}^{+}$cells, and $\mathrm{BrdU}^{+} / \mathrm{GFAP}^{+}$cells (Table 5).

After quantifying the number of $\mathrm{BrdU}^{+}$cells in the three subregions of the hippocampus, we found that in the CA1 and CA2/3 areas, the density of the $\mathrm{BrdU}^{+}$cells in the CUS/standard group was significantly lower than that in the control group $(p=0.005 ; p=0.021)$. A similar trend was also found in the DG. $(p=0.054)$. Moreover, the density of $\mathrm{BrdU}^{+}$cells in the three areas in the CUS/ running group was significantly higher than that in the CUS/standard group $(p=0.030 ; p=0.018 ; p=0.005)$ (Fig. 5B). There were $0.88,0.805$, and 0.868 power to detect an effect size of 1.016, 0.918, and 0.997 for the 


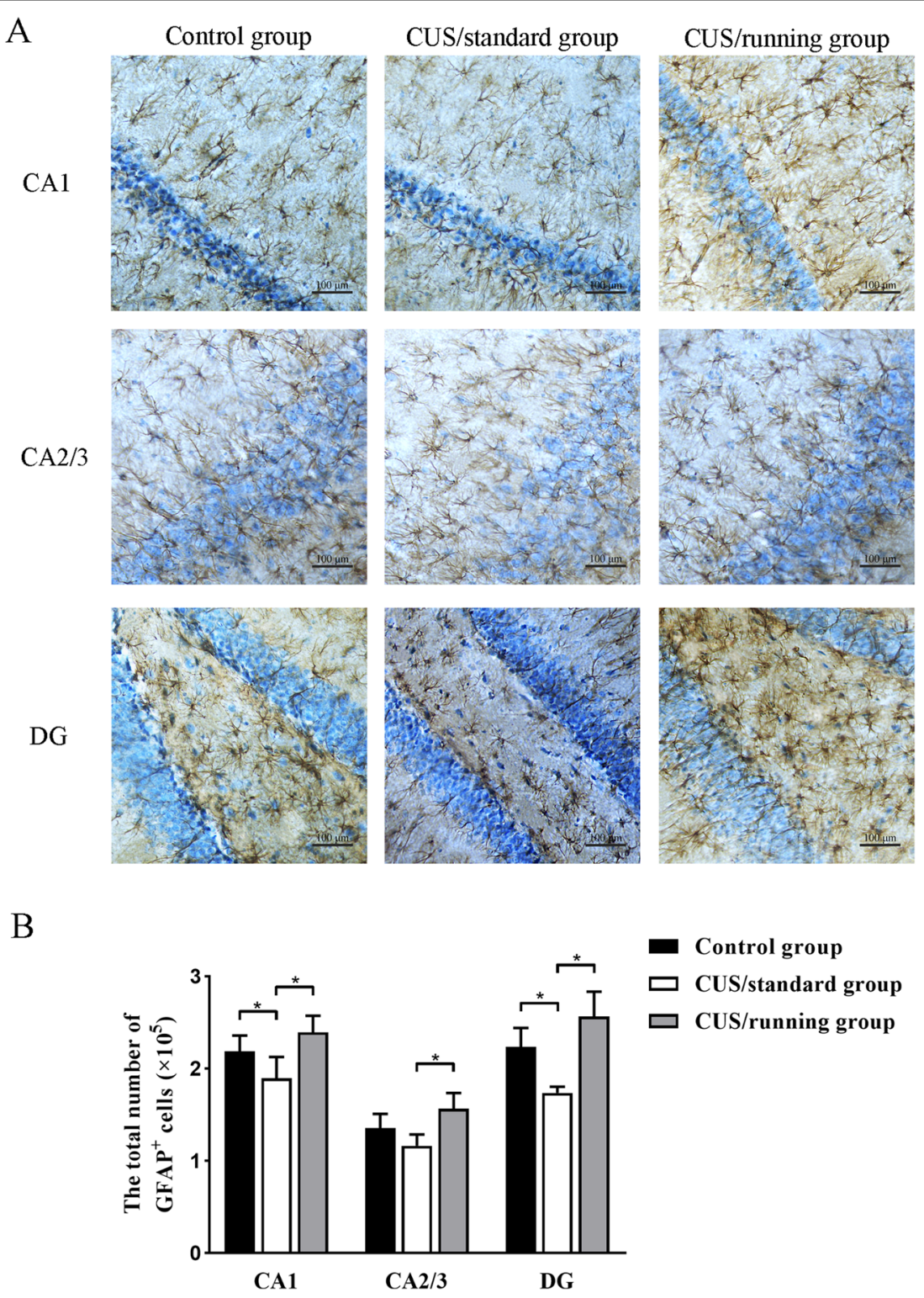

Fig. 4 The positive effects of running exercise on the total number of $\mathrm{GFAP}^{+}$cells in the hippocampus of CUS rats. A Representative pictures of immunohistochemical staining with an anti-GFAP antibody in the three subregions of the hippocampus in the control group, CUS/standard group, and the CUS/running group. Bar $=100 \mu \mathrm{m}$. B The total number of GFAP ${ }^{+}$cells in the CA1 region, CA2/3 region and DG in the control group $(n=5)$, the CUS/standard group $(n=5)$, and the CUS/cunning group $(n=5)$ (mean \pm SD). Asterisk indicates $p<0.05$. CUS chronic unpredictable stress, GFAP glial fibrillary acidic protein.

density of the BrdU ${ }^{+}$cells in the CA1, CA2/3, and DG, respectively.

The density of $\mathrm{GFAP}^{+}$cells in the hippocampal subregions in the three groups $(p=0.033, p=0.062$, and $p=$ 0.042 for control vs. CUS/standard in the CA1 region, CA2/3 region, and DG, respectively; $p=0.026, p=0.033$, and $p=0.039$ for CUS/standard vs. CUS/running in the CA1 region, CA2/3 region, and DG, respectively) (Fig. 5C) as well as the density of $\mathrm{BrdU}^{+} / \mathrm{GFAP}^{+}$cells were also quantified. In the CA1 area and DG, the density of
$\mathrm{BrdU}^{+} / \mathrm{GFAP}^{+}$cells in the CUS/standard group was significantly lower than that in the control group $(p=0.024$; $p=0.013$ ), but there was no significant difference in the density of $\mathrm{BrdU}^{+} / \mathrm{GFAP}^{+}$cells between these groups in the CA2/3 area $(p=0.109)$. In the three areas, the CUS/ running group showed a significantly higher density of $\mathrm{BrdU}^{+} / \mathrm{GFAP}^{+}$cells than the CUS/standard group ( $p=$ $0.001 ; p=0.014 ; p=0.000$ ) (Fig. 5D). These results indicated that running exercise had a beneficial effect on the generation of newborn astrocytes. There were 0.717, 
Table 4 The number of GFAP $^{+}$cell numbers.

\begin{tabular}{llll}
\hline & Control group & $\begin{array}{l}\text { CUS/ } \\
\text { standard group }\end{array}$ & $\begin{array}{l}\text { CUS/ } \\
\text { running group }\end{array}$ \\
\hline $\begin{array}{lll}\text { Number of } \mathrm{GFAP}^{+} \text {cells }\left(\times 10^{5}\right) \\
\text { CA1 }\end{array}$ & $2.19 \pm 0.17$ & $1.89 \pm 0.23$ & $2.4 \pm 0.18$ \\
CV & 0.071 & 0.109 & 0.067 \\
CE & 0.002 & 0.002 & 0.002 \\
CA2/3 & $1.36 \pm 0.15$ & $1.16 \pm 0.12$ & $1.56 \pm 0.17$ \\
CV & 0.102 & 0.092 & 0.098 \\
CE & 0.003 & 0.003 & 0.003 \\
DG & $2.24 \pm 0.21$ & $1.74 \pm 0.07$ & $2.57 \pm 0.27$ \\
CV & 0.082 & 0.034 & 0.095 \\
CE & 0.002 & 0.002 & 0.002 \\
\hline
\end{tabular}

Number of $\mathrm{GFAP}^{+}$is represented as mean \pm standard deviation (SD).

CUS chronic unpredictable stress, GFAP glial fibrillary acidic protein, CV coefficient of variation, $C E$ coefficient of error.

0.631 , and 0.641 power to detect an effect size of 0.83 , 0.756 , and 0.765 for the density of the $\mathrm{GFAP}^{+}$cells in the CA1, CA2/3, and DG, respectively. There were 0.999, 0.813 , and 0.996 power to detect an effect size of 1.578 , 0.927 , and 1.462 for the density of the $\mathrm{BrdU}^{+} / \mathrm{GFAP}^{+}$cells in the CA1, CA2/3, and DG, respectively.

\section{Discussion}

The CUS model, as a classic animal model of depression, has often been used to simulate a depressive state ${ }^{52}$. In the present study, rats were exposed to CUS, and the SPT was used to evaluate anhedonia, the core symptom of depression. We found that 5 weeks of CUS intervention significantly reduced body weight, sucrose preference, and hippocampal volume. These results were consistent with previous studies. For example, we previously reported the body weights of rats are decreased after CUS intervention $^{43,44}$. Furthermore, animals exposed to CUS show a reduced preference for sucrose solutions ${ }^{39,43,44}$ and hippocampal volume ${ }^{10}$. Therefore, our results indicated that our depression animal model was successfully established. Mounting evidence from postmortem and animal studies supports the contention that alterations in the number of astrocytes in the hippocampus are closely associated with depression $^{19,20,53}$. In our present study, using an unbiased stereological technique, we found that CUS obviously decreased the number of $\mathrm{GFAP}^{+}$astrocytes in the hippocampus of rats. Similarly, Czéh et al. used a stereological method to study the changes in $\mathrm{GFAP}^{+}$astrocytes in the hippocampus of male tree shrews after long-term psychosocial stress and found that the number of astrocytes in the hippocampus was consistently decreased ${ }^{10}$. However, there were three main differences between our study and the study by Czéh et al. First, our animal model was different from the one used by Czéh et al. We simulated a depressive state in rats by applying different stressors to generate the CUS model, which is the most widely used and typical animal model of depression ${ }^{52,54}$, whereas the chronic psychosocial stress paradigm used in the male tree shrews produced a depressive state by establishing a stable dominant/subordinate relationship in which the subordinates showed distinct stress-induced behavioral changes similar to those observed in depressed patients ${ }^{55-57}$. However, not all depressed patients suffer from the influence of dominant/subordinate relationships. Therefore, the chronic psychosocial stress model would inevitably have limitations in simulating general depressive symptoms. Second, Czéh et al. measured changes in adrenal and testis weight rather than the SPT, the "gold standard" test for assessing the core symptoms of depression in animal models, to evaluate the depressive state of animals in their study. Therefore, our results provide a more comprehensive exposition of the relationship between the number of hippocampal astrocytes and depression-like behavior. Finally, Czéh et al. found astroglial loss in the hippocampus but did not report the astroglial changes specific to each subregion of the hippocampus. As previously noted, the hippocampal formation is one of the most sensitive and susceptible regions of the CNS, and its subregions have specific structural connectivity and functional roles ${ }^{21}$. In this study, the number of astrocytes in each subregion of the hippocampus was accurately quantified. Our results showed that CUS reduced the number of astrocytes in the CA1 region and DG of the hippocampus, but not the CA2/3 region. Why did the changes in astrocytes differ across hippocampal subregions in depressed rats? In a clinical study in which MRI brain scans were used to detect the volume of hippocampal subregions in depressed patients and healthy control subjects, the left CA1 region emerged as a potential marker of depression ${ }^{58}$. Some studies have shown that the CA1 region is closely related to the pathogenesis of depression models ${ }^{59,60}$. Furthermore, in the CNS of adult mammals, neurogenesis mainly occurs in two regions, one of which is the DG. Adult neural stem cells can self-renew or differentiate into astrocytes or other cells in response to specific stimuli ${ }^{61}$. Alves et al. found that chronic stress can decrease adult neurogenesis in the DG in rats ${ }^{62}$, which might lead to a reduction in the number of neural stem cells that differentiate into astrocytes. Thus, we speculated that regional sensitivity to stress and the effect of stress on astrocyte formation might explain the decrease in the number of astrocytes in the CA1 region and DG in rats after CUS intervention; however, the specific causes of this decrease need to be further studied. We are the first group to study the changes in the number of astrocytes in the hippocampal subregions in CUS rats using accurate stereological 


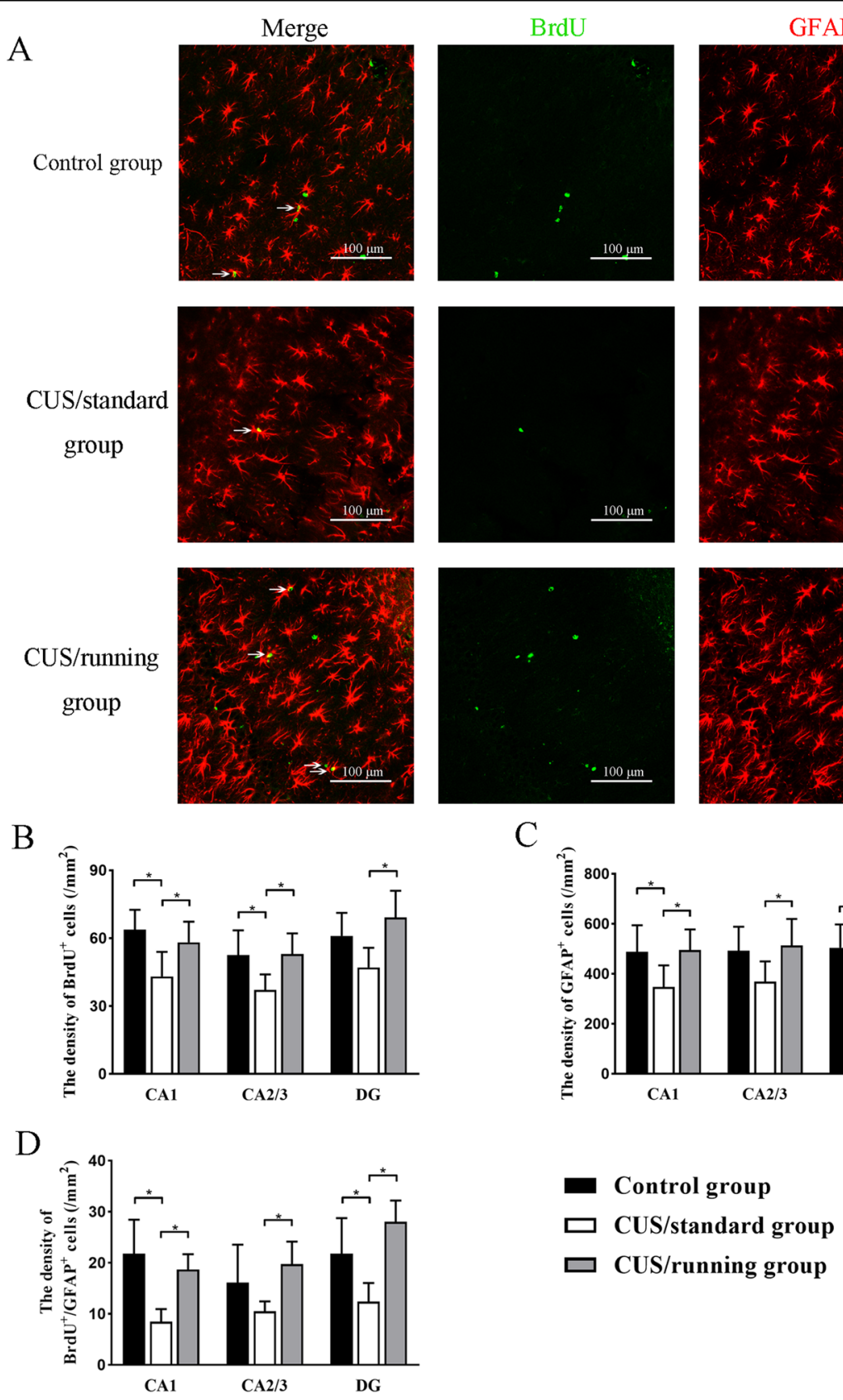

Fig. 5 The positive effects of running exercise on the newborn astrocytes in the hippocampus of CUS rats. A Representative pictures of immunofluorescence staining with an anti-BrdU antibody and an anti-GFAP antibody in the hippocampus in the control group, CUS/standard group and the CUS/running group. Bar $=100 \mu \mathrm{m}$. B Quantification of $\mathrm{BrdU}^{+}$cells in the three subregions of the hippocampus for the three groups of rats ( $n=5$ per group, mean \pm SD). C Quantification of GFAP cells in the three subregions of the hippocampus for the three groups of rats $(n=5$ per group, mean $\pm \mathrm{SD}$ ). D Quantification of $\mathrm{BrdU}^{+} / \mathrm{GFAP}^{+}$cells in the three subregions of the hippocampus for the three groups of rats $(n=5$ per group, mean \pm SD). Asterisk indicates $p<0.05$. CUS chronic unpredictable stress, GFAP glial fibrillary acidic protein, BrdU bromodeoxyuridine.

techniques, and we found that the change in the number of astrocytes induced by chronic stress in each subregion of the hippocampus was different.

Both clinical studies and animal studies have demonstrated that running exercise has positive effects on depression ${ }^{32,63-65}$. Lapmanee et al. compared the effects of running exercise with those of common antidepressant drugs such as fluoxetine and found that both treatments alleviate anxiety- and depressive-like behaviors in stressed male rats ${ }^{66}$. Consistent with these studies, we found that 6 weeks of running exercise significantly reversed the decreased percentage of sucrose preference of CUS rats, 
Table 5 The density of $\mathrm{BrdU}^{+}, \mathrm{GFAP}^{+}$, and $\mathrm{BrdU}^{+}$I GFAP $^{+}$cell.

\begin{tabular}{|c|c|c|c|}
\hline & Control group & $\begin{array}{l}\text { CUS/ } \\
\text { standard group }\end{array}$ & $\begin{array}{l}\text { CUS/running } \\
\text { group }\end{array}$ \\
\hline \multicolumn{4}{|c|}{ Density of $\mathrm{BrdU}^{+}$cells $\left(/ \mathrm{mm}^{2}\right)$} \\
\hline CA1 & $63.79 \pm 7.88$ & $43.06 \pm 9.78$ & $58.18 \pm 8.2$ \\
\hline CV & 0.124 & 0.212 & 0.141 \\
\hline $\mathrm{CA} 2 / 3$ & $52.51 \pm 9.8$ & $37.18 \pm 6.1$ & $53.05 \pm 8.13$ \\
\hline CV & 0.187 & 0.164 & 0.153 \\
\hline DG & $61 \pm 9.16$ & $47.07 \pm 7.78$ & $69.17 \pm 10.52$ \\
\hline CV & 0.15 & 0.165 & 0.152 \\
\hline \multicolumn{4}{|c|}{ Density of GFAP ${ }^{+}$cells $\left(/ \mathrm{mm}^{2}\right)$} \\
\hline CA1 & $488.18 \pm 94.81$ & $347.28 \pm 77.09$ & $494.95 \pm 74$ \\
\hline CV & 0.194 & 0.222 & 0.15 \\
\hline $\mathrm{CA} 2 / 3$ & $492.24 \pm 86.13$ & $368.18 \pm 72.6$ & $513.39 \pm 95.3$ \\
\hline CV & 0.175 & 0.197 & 0.186 \\
\hline DG & $504.28 \pm 83.78$ & $352.34 \pm 85.15$ & $506.7 \pm 111.3$ \\
\hline CV & 0.166 & 0.242 & 0.22 \\
\hline \multicolumn{4}{|c|}{ Density of $\mathrm{BrdU}^{+} / \mathrm{GFAP}^{+}$cells $\left(/ \mathrm{mm}^{2}\right)$} \\
\hline CA1 & $21.82 \pm 5.94$ & $8.5 \pm 2.2$ & $18.7 \pm 2.67$ \\
\hline $\mathrm{CV}$ & 0.272 & 0.259 & 0.143 \\
\hline $\mathrm{CA} 2 / 3$ & $16.12 \pm 6.64$ & $10.52 \pm 1.72$ & $19.72 \pm 3.93$ \\
\hline CV & 0.412 & 0.163 & 0.199 \\
\hline DG & $21.8 \pm 6.21$ & $12.43 \pm 3.25$ & $28.04 \pm 3.7$ \\
\hline CV & 0.285 & 0.261 & 0.132 \\
\hline
\end{tabular}

Density of $\mathrm{BrdU}^{+}, \mathrm{GFAP}^{+}$, and $\mathrm{BrdU}^{+} / \mathrm{GFAP}^{+}$cells are represented as mean \pm standard deviation (SD).

CUS chronic unpredictable stress, GFAP glial fibrillary acidic protein, BrdU bromodeoxyuridine, CV coefficient of variation.

indicating that running exercise improved anhedonia in our experiment. Meanwhile, we found that running exercise significantly reversed the declined hippocampal volume of CUS rats. Therefore, the results of our present study further confirmed that exercise might have a therapeutic effect on depression. It has been reported that antidepressant drugs act on astrocytes and exert their therapeutic effects by increasing ATP gliotransmission ${ }^{67}$. Cobb et al. also found no reduction in the density of astrocytes in the hippocampus of depressed patients taking an antidepressant drug ${ }^{20}$. Thus, the number of astrocytes is closely related to depression and antidepressant therapy, but whether astrocytes are involved in the antidepressant effect of running exercise is still unknown. In our study, we found that 6 weeks of running exercise also significantly increased the number of astrocytes in the three areas of the hippocampus in CUS rats, which indicated that running exercise had beneficial effects on the number of astrocytes in the hippocampus of CUS rats.
Therefore, we are the first to report that changes in astrocytes might participate in the mechanism underlying the antidepressant effects of running exercise.

What causes the running exercise-induced change in the number of astrocytes in the hippocampus? We speculated that changes in the number of newly generated astrocytes might be one of the reasons for the change in the number of astrocytes in the hippocampus. In the current study, we used immunofluorescence to test this hypothesis. The density of $\mathrm{BrdU}^{+}$cells was evaluated to determine the number of newborn cells, and the density of $\mathrm{BrdU}^{+} / \mathrm{GFAP}^{+}$cells was measured to determine the number of newborn astrocytes. Our present results showed that 5 weeks of CUS intervention decreased the number of newborn cells in the three regions of the hippocampus and that 6 weeks of running exercise obviously increased the number of newborn cells in the three hippocampal subregions in CUS rats. Praag et al. found that voluntary wheel running increases the total number of $\mathrm{BrdU}^{+}$cells in the DG in normal mice ${ }^{68}$, and it has been demonstrated that both forced and voluntary exercise increase the number of $\mathrm{BrdU}^{+}$cells in the DG in normal rats ${ }^{69}$. However, the alterations in the number of newborn cells in the CA1 and CA2/3 regions and in depression after exercise are still unclear. We found that running exercise increased the number of newborn cells in the DG, CA1 region, and CA2/3 region of the hippocampus. As already noted, the DG of the hippocampus is one of the regions, in which neurogenesis occurs in the CNS of adult mammals ${ }^{61}$, and the process of adult neurogenesis encompasses proliferation, differentiation, migration, and functional integration into the pre-existing circuitry ${ }^{70}$. Therefore, we speculated that the increase in the number of newborn cells in the CA1 and CA2/3 regions might have resulted from migration of cells from the DG to these regions. Thus, our present results suggest that running exercise improves neurogenesis in the three subregions of the hippocampus in depressed rats. Although many studies have affirmed the positive effects of running exercise on newborn astrocytes in many brain regions in normal animals ${ }^{37,38}$, it is unclear whether running exercise can promote the generation of new astrocytes in hippocampal subregions in depression. In the current study, we found that the density of $\mathrm{BrdU}^{+} /$ $\mathrm{GFAP}^{+}$cells was reduced in the CA1 region and DG in CUS rats and that 6 weeks of running exercise significantly increased the number of newborn astrocytes in the three regions of the hippocampus in CUS rats, which indicates that newly generated astrocytes in the hippocampus play a role in the antidepressant effect of running exercise. Therefore, we speculated that newborn astrocytes in the hippocampus might be a new target for antidepressant therapy. However, it is not clear whether the increase in the number of newborn astrocytes in the hippocampus of depressed rats after running exercise was due to the increased numbers of newborn cells or the increased 
differentiation of newborn cells into astrocytes. In this study, we found that running exercise increased the number of newborn cells in the hippocampus. Therefore, in the future, whether newborn cells differentiate into astrocytes is more than other cells in depression models after running exercise should be studied.

In the present study, we found that running exercise could increase the number of astrocytes and the density of newborn astrocytes in the hippocampus of depressive-like rats. What might be the mechanism for the antidepression of the astrocytes increase induced by running exercise? It has been reported that the endogenous ATP released by astrocytes ${ }^{17}$ and the astrocyte-specific glutamate transporters ${ }^{71}$ might be related to the depression. Therefore, we speculated that the astrocyte increase induced by running exercise might induce antidepressant-like effects through affecting the astrocyterelated endogenous ATP and the astrocyte-specific glutamate transporters. The exact mechanism for the antidepression of the exercise-induced astrocyte increase needs to be further investigated in the future. The understanding of the mechanism might have important implications for exploring the new treatment of human depression.

In conclusion, depression is characterized by high recurrence and suicide rates. The antidepressant effect of running exercise as a behavioral intervention was further confirmed in this study. In our present study, we observed a loss of astrocytes in the CA1 region and DG of the hippocampus in depressed rats, which further confirmed that astrocytes in the hippocampus are involved in the pathological process of depression. More importantly, our present results revealed that running exercise can reverse the decreases in the number of astrocytes and the density of newborn astrocytes in the three subregions of the hippocampus in depressed rats and increase sucrose consumption. Our findings provide new insights into the role of astrocytes in depression and the antidepressant effect of running exercise, which might provide structural bases for exploring antidepressant therapy.

\section{Acknowledgements}

This work was supported by the National Natural Science Foundation of China (NSFC 81871073).

\footnotetext{
Author details

${ }^{1}$ Department of Histology and Embryology, Chongqing Medical University, 400016 Chongqing, P. R. China. ${ }^{2}$ Laboratory of Stem Cells and Tissue Engineering, Chongqing Medical University, 400016 Chongqing, P. R. China. ${ }^{3}$ Department of Physiology, Chongqing Medical University, 400016 Chongqing, P. R. China. ${ }^{4}$ Department of Pathophysiology, Chongqing Medical University, 400016 Chongqing, P. R. China. ${ }^{5}$ Department of Radioactive Medicine, Chongqing Medical University, 400016 Chongqing, P. R. China. ${ }^{6}$ Lab Teaching \& Management Center, Chongqing Medical University, 400016 Chongqing, P. R. China. ${ }^{7}$ Institute of Life Science, Chongqing Medical University, 400016 Chongqing, P. R. China
}

\section{Publisher's note}

Springer Nature remains neutral with regard to jurisdictional claims in published maps and institutional affiliations.

Supplementary Information The online version contains supplementary material available at https://doi.org/10.1038/s41398-021-01216-x.

Received: 18 August 2020 Revised: 6 January 2021 Accepted: 13 January 2021

Published online: 01 February 2021

\section{References}

1. National Collaborating Centre for Mental Health (UK). Depression: The Treatment and Management of Depression in Adults (Updated Edition) (British Psychological Society, 2010).

2. Krishnan, V. \& Nestler, E. J. The molecular neurobiology of depression. Nature 455, 894-902 (2008).

3. Moser, M. B., Moser, E. I., Forrest, E., Andersen, P. \& Morris, R. G. M. Spatial learning with a minislab in the dorsal hippocampus. Proc. Natl Acad. Sci. USA 92, 9697-9701 (1995).

4. Fournier, N. M. \& Duman, R. S. Illuminating hippocampal control of fear memory and anxiety. Neuron 77, 803-806 (2013).

5. Sapolsky, R. M. Depression, antidepressants, and the shrinking hippocampus. Proc. Natl Acad. Sci. USA 98, 12320-12322 (2001).

6. Bremner, J. D. et al. Hippocampal volume reduction in major depression. Am. J. Psychiatry 157, 115-118 (2000).

7. Neumeister, A. et al. Reduced hippocampal volume in unmedicated, remitted patients with major depression versus control subjects. Biol. Psychiatry 57, 935-937 (2005).

8. Alonso, R. et al. Blockade of CRF1 or V1b receptors reverses stress-induced suppression of neurogenesis in a mouse model of depression. Mol. Psychiatry 9. 278-286 (2004)

9. Czéh, B. et al. Examining SLV-323, a novel NK1 receptor antagonist, in a chronic psychosocial stress model for depression. Psychopharmacology $\mathbf{1 8 0}$, 548-557 (2005).

10. Czéh, B., Simon, M., Schmelting, B., Hiemke, C. \& Fuchs, E. Astroglial plasticity in the hippocampus is affected by chronic psychosocial stress and concomitant fluoxetine treatment. Neuropsychopharmacology 31, 1616-1626 (2006).

11. Herculano-Houzel, S. The glia/neuron ratio: how it varies uniformly across brain structures and species and what that means for brain physiology and evolution. Glia 62, 1377-1391 (2014).

12. Rowitch, D. H. \& Kriegstein, A. R. Developmental genetics of vertebrate glial-cell specification. Nature 468, 214-222 (2010).

13. Verkhratsky, A. \& Butt, A. Glial Physiology and Pathophysiology (John Wiley \& Sons, Ltd., 2013).

14. Qi X.-R., Kamphuis W. \& Shan L. Astrocyte changes in the prefrontal cortex from aged non-suicidal depressed patients. Front. Cell Neurosci. https://doi.org/ 10.3389/fncel.2019.00503 (2019).

15. Rajkowska, G. \& Stockmeier, C. Astrocyte pathology in major depressive disorder: insights from human postmortem brain tissue. Curr. Drug Targets $\mathbf{1 4}$ 1225-1236 (2013)

16. Cui, Y. et al. Astroglial Kir4.1 in the lateral habenula drives neuronal bursts in depression. Nature 554, 323-327 (2018).

17. Cao, X. et al. Astrocyte-derived ATP modulates depressive-like behaviors. Nat Med. 19, 773-777 (2013).

18. Rajkowska, G. et al. Astrocyte pathology in the ventral prefrontal white matter in depression. J. Psychiatr. Res. 102, 150-158 (2018).

19. Müller, M. B. et al. Neither major depression nor glucocorticoid treatment affects the cellular integrity of the human hippocampus. Eur. J. Neurosci. 14 1603-1612 (2001).

20. Cobb, J. A. et al. Density of GFAP-immunoreactive astrocytes is decreased in left hippocampi in major depressive disorder. Neuroscience 316, 209-220 (2016).

21. Andersen P., Morris R., Amaral D., Bliss T. \& O' Keefe J. The Hippocampus Book (Oxford University Press, 2006).

22. Leuner, B. \& Gould, E. Structural plasticity and hippocampal function. Annu. Rev. Psychol. 61, 111-140 (2010).

23. Pittenger, C. \& Duman, R. S. Stress, depression and neuroplasticity: a convergence of mechanisms. Neuropsychopharmacology 33, 88-109 (2008). 
24. Alfarez, D. N., Joëls, M. \& Krugers, H. J. Chronic unpredictable stress impairs long-term potentiation in rat hippocampal CA1 area and dentate gyrus in vitro. Eur. J. Neurosci. 17, 1928-1934 (2003).

25. Jacobs, B. L., van Praag, H. \& Gage, F. H. Adult brain neurogenesis and psychiatry: a novel theory of depression. Mol. Psychiatry 5, 262-269 (2000).

26. Frisén, J. Neurogenesis and gliogenesis in nervous system plasticity and repair. Annu. Rev. Cell Dev. Biol. 32, 127-141 (2016).

27. Yamaguchi, M. et al. Neural stem cells and neuro/gliogenesis in the central nervous system: understanding the structural and functional plasticity of the developing, mature, and diseased brain. J. Physiol. Sci. 66, 197-206 (2016).

28. Kvam, S., Kleppe, C. L., Nordhus, I. H. \& Hovland, A. Exercise as a treatment for depression: a meta-analysis. J. Affect Disord. 202, 67-86 (2016).

29. Knöchel, C. et al. Cognitive and behavioural effects of physical exercise in psychiatric patients. Prog. Neurobiol. 96, 46-68 (2012).

30. Chen, L.-M. et al. Running exercise protects the capillaries in white matter in a rat model of depression. J. Comp. Neurol. 524, 3577-3586 (2016).

31. Xiao, Q. et al. Exercise protects myelinated fibers of white matter in a rat model of depression. J. Comp. Neurol. 526, 537-549 (2018).

32. Wang, $Y$. et al. Astrocytes activation contributes to the antidepressant-like effect of ketamine but not scopolamine. Pharmacol. Biochem. Behav. 170, 1-8 (2018).

33. Wang, Y. et al. Inhibition of activated astrocyte ameliorates lipopolysaccharideinduced depressive-like behaviors. J. Affect Disord. 242, 52-59 (2019).

34. Saur, L. et al. Physical exercise increases GFAP expression and induces morphological changes in hippocampal astrocytes. Brain Struct. Funct. 219, 293-302 (2014)

35. Li, J. et al. Increased astrocyte proliferation in rats after running exercise. Neurosci. Lett. 386, 160-164 (2005).

36. de Senna, P. N. et al. Physical exercise reverses spatial memory deficit and induces hippocampal astrocyte plasticity in diabetic rats. Brain Res. 1655 242-251 (2017)

37. Ehninger, D. Regional effects of wheel running and environmental enrichment on cell genesis and microglia proliferation in the adult murine neocortex. Cereb. Cortex 13, 845-851 (2003).

38. Uda, M., Ishido, M., Kami, K. \& Masuhara, M. Effects of chronic treadmill running on neurogenesis in the dentate gyrus of the hippocampus of adult rat. Brain Res. 1104, 64-72 (2006).

39. Willner P., Towell A., Sampson D., Sophokleous S. \& Muscat R. Reduction of sucrose preference by chronic unpredictable mild stress, and its restoration by a tricyclic antidepressant. Psychopharmacology (Berl.) https://doi.org/10.1007/ BF00187257 (1987).

40. Banasr, M. et al. Chronic unpredictable stress decreases cell proliferation in the cerebral cortex of the adult rat. Biol. Psychiatry 62, 496-504 (2007).

41. Seney, M. L., Walsh, C., Stolakis, R. \& Sibille, E. Neonatal testosterone partially organizes sex differences in stress-induced emotionality in mice. Neurobiol. Dis. 46, 486-496 (2012).

42. Luo, Y. et al. Running exercise protects oligodendrocytes in the medial prefrontal cortex in chronic unpredictable stress rat model. Transl. Psychiatry 9 322 (2019).

43. Tang, J. et al. The effects of running exercise on oligodendrocytes in the hippocampus of rats with depression induced by chronic unpredictable stress. Brain Res. Bull. 149, 1-10 (2019).

44. Liang, $X$. et al. Exercise improves depressive symptoms by increasing the number of excitatory synapses in the hippocampus of CUS-Induced depression model rats. Behav. Brain Res. 374, 112115 (2019).

45. Qiu, L., Zhu, C.-L., Wang, X.-Y. \& Xu, F.-L. Changes of cell proliferation and differentiation in the developing brain of mouse. Neurosci. Bull. 23, 46-52 (2007).

46. Wojtowicz J. M. \& Kee N. BrdU assay for neurogenesis in rodents. Nat. Protoc. https://doi.org/10.1038/nprot.2006.224 (2006).

47. Mateus-Pinheiro, A. et al. Sustained remission from depressive-like behavior depends on hippocampal neurogenesis. Transl. Psychiatry https://doi.org/ 10.1038/tp.2012.141 (2013)

48. Gundersen, H. J. G. et al. Some new, simple and efficient stereological methods and their use in pathological research and diagnosis. APMIS https:// doi.org/10.1111/j.1699-0463.1988.tb05320.x (1988).
49. Tang, Y. \& Nyengaard, J. R. A stereological method for estimating the total length and size of myelin fibers in human brain white matter. J. Neurosci. Methods https://doi.org/10.1016/S0165-0270(97)02228-0 (1997).

50. Buhl, E. H. \& Dann, J. F. Cytoarchitecture, neuronal composition, and entorhinal afferents of the flying fox hippocampus. Hippocampus 1, 131-152 (1991).

51. Gundersen, H. J. G., Jensen, E. B. V., Kiêu, K. \& Nielsen, J. The efficiency of systematic sampling in stereology - Reconsidered. J. Microsc. https://doi.org/ 10.1046/j.1365-2818.1999.00457.x (1999)

52. Antoniuk, S., Bijata, M., Ponimaskin, E. \& Wlodarczyk, J. Chronic unpredictable mild stress for modeling depression in rodents: meta-analysis of model reliability. Neurosci. Biobehav. Rev. 99, 101-116 (2019).

53. Stockmeier, C. A. et al. Cellular changes in the postmortem hippocampus in major depression. Biol. Psychiatry 56, 640-650 (2004).

54. Willner, P. The chronic mild stress (CMS) model of depression: history, evaluation and usage. Neurobiol. Stress 6, 78-93 (2017).

55. Fuchs, E. Social stress in tree shrews as an animal model of depression: an example of a behavioral model of a CNS disorder. CNS Spectr. 10, 182-190 (2005).

56. Kampen, M., van, Kramer, M., Hiemke, C., Flügge, G. \& Fuchs, E. The chronic psychosocial stress paradigm in male tree shrews: evaluation of a novel animal model for depressive disorders. Stress 5, 37-46 (2002).

57. Fuchs, E., Czéh, B. \& Flügge, G. Examining novel concepts of the pathophysiology of depression in the chronic psychosocial stress paradigm in tree shrews. Behav. Pharmacol. 15, 315-325 (2004).

58. Roddy, D. W. et al. The hippocampus in depression: more than the sum of its parts? Advanced hippocampal substructure segmentation in depression. Biol. Psychiatry 85, 487-497 (2019).

59. Song, Q. et al. Hippocampal CA1 $\beta C$ aMKII mediates neuroinflammatory responses via COX-2/PGE2 signaling pathways in depression. J. Neuroinflammation 15, 338 (2018).

60. Zhang, T. R. et al. Negative memory engrams in the hippocampus enhance the susceptibility to chronic social defeat stress. J. Neurosci. 39, 7576-7590 (2019).

61. Vieira, M. S. et al. Neural stem cell differentiation into mature neurons: mechanisms of regulation and biotechnological applications. Biotechnol. Adv. 36, 1946-1970 (2018).

62. Alves, N. D. et al. Chronic stress targets adult neurogenesis preferentially in the suprapyramidal blade of the rat dorsal dentate gyrus. Brain Struct. Funct. 223, 415-428 (2018)

63. Schuch, F. B. et al. Exercise as a treatment for depression: a meta-analysis adjusting for publication bias. J. Psychiatr. Res. 77, 42-51 (2016).

64. Chen, C. et al. The role of medial prefrontal corticosterone and dopamine in the antidepressant-like effect of exercise. Psychoneuroendocrinology 69, 1-9 (2016).

65. Hong, Y.-P., Lee, H.-C. \& Kim, H.-T. Treadmill exercise after social isolation increases the levels of NGF, BDNF, and synapsin I to induce survival of neurons in the hippocampus, and improves depression-like behavior. J. Exerc. Nutr. Biochem. 19, 11-18 (2015)

66. Lapmanee, S., Charoenphandhu, J. \& Charoenphandhu, N. Beneficial effects of fluoxetine, reboxetine, venlafaxine, and voluntary running exercise in stressed male rats with anxiety- and depression-like behaviors. Behav. Brain Res. 250 316-325 (2013)

67. Kinoshita, M. et al. Anti-depressant fluoxetine reveals its therapeutic effect via astrocytes. EBioMedicine 32, 72-83 (2018).

68. van Praag, H., Kempermann, G. \& Gage, F. H. Running increases cell proliferation and neurogenesis in the adult mouse dentate gyrus. Nat. Neurosci. 2 , 266-270 (1999).

69. Leasure, J. L. \& Jones, M. Forced and voluntary exercise differentially affect brain and behavior. Neuroscience 156, 456-465 (2008).

70. Ehninger, D. \& Kempermann, G. Neurogenesis in the adult hippocampus. Cell Tissue Res. 331, 243-250 (2008).

71. Moriguchi, S. et al. Glutamatergic neurometabolite levels in major depressive disorder: a systematic review and meta-analysis of proton magnetic resonance spectroscopy studies. Mol. Psychiatry https://doi.org/10.1038/s41380-018-02529. (2019). 